\title{
Seismic wave propagation in anisotropic ice - Part 2: Effects of crystal anisotropy in geophysical data
}

\author{
A. Diez ${ }^{1,2, *}$, O. Eisen ${ }^{1,3}$, C. Hofstede ${ }^{1}$, A. Lambrecht ${ }^{4}$, C. Mayer ${ }^{4}$, H. Miller ${ }^{1}$, D. Steinhage ${ }^{1}$, T. Binder ${ }^{5, * *}$, and \\ I. Weikusat ${ }^{1,6}$ \\ ${ }^{1}$ Alfred-Wegener-Institut Helmholtz-Zentrum für Polar- und Meeresforschung, Bremerhaven, Germany \\ ${ }^{2}$ Karlsruhe Institute of Technology, Karlsruhe, Germany \\ ${ }^{3}$ Department Geosciences, University of Bremen, Bremen, Germany \\ ${ }^{4}$ Bavarian Academy for Sciences and Humanities, Munich, Germany \\ ${ }^{5}$ Interdisciplinary Center for Scientific Computing, University of Heidelberg, Heidelberg, Germany \\ ${ }^{6}$ Department of Geosciences, Eberhard Karls University of Tübingen, Tübingen, Germany \\ *now at: Scripps Institution of Oceanography, University of California, San Diego, USA \\ ** now at: Alfred-Wegener-Institut Helmholtz-Zentrum für Polar- und Meeresforschung, Bremerhaven, Germany
}

Correspondence to: A. Diez (adiez@ucsd.edu)

Received: 18 June 2014 - Published in The Cryosphere Discuss.: 4 August 2014

Revised: 10 January 2015 - Accepted: 27 January 2015 - Published: 20 February 2015

\begin{abstract}
We investigate the propagation of seismic waves in anisotropic ice. Two effects are important: (i) sudden changes in crystal orientation fabric (COF) lead to englacial reflections; (ii) the anisotropic fabric induces an angle dependency on the seismic velocities and, thus, recorded travel times. Velocities calculated from the polycrystal elasticity tensor derived for the anisotropic fabric from measured COF eigenvalues of the EDML ice core, Antarctica, show good agreement with the velocity trend determined from vertical seismic profiling. The agreement of the absolute velocity values, however, depends on the choice of the monocrystal elasticity tensor used for the calculation of the polycrystal properties. We make use of abrupt changes in $\mathrm{COF}$ as a common reflection mechanism for seismic and radar data below the firnice transition to determine COF-induced reflections in either data set by joint comparison with ice-core data. Our results highlight the possibility to complement regional radar surveys with local, surface-based seismic experiments to separate isochrones in radar data from other mechanisms. This is important for the reconnaissance of future ice-core drill sites, where accurate isochrone (i.e. non-COF) layer integrity allows for synchronization with other cores, as well as studies of ice dynamics considering non-homogeneous ice viscosity from preferred crystal orientations.
\end{abstract}

\section{Introduction}

To understand the behaviour of glaciers and ice sheets, we need measurements to determine the conditions of glaciers at the surface, at the base and within the ice mass. In situ measurement of englacial physical properties can only be gained by the drilling of boreholes and analysis of ice cores. From an ice core, information in high vertical resolution can be gained at one specific location on properties such as density, conductivity or the size and orientation of ice crystals (Cuffey and Paterson, 2010). To be able to collect information about the spatial distribution of these physical properties beyond the $\sim 10 \mathrm{~cm}$ resolution of ice cores, we use surface-based radar and seismic measurements to determine englacial conditions.

The propagation of radar waves is mainly influenced by density, conductivity, crystal orientation fabric (COF) and temperature. The propagation of seismic waves is mainly influenced by density, COF and temperature. The influence of the temperature on the wave velocity is rather small in both cases (e.g. Matsuoka et al., 1997; Gammon et al., 1983). Below the firn-ice transition the common mechanism influencing the propagation of seismic and radar waves is a preferred orientation of the anisotropic, hexagonal ice crystals. This fabric anisotropy is normally described in the form of the $\mathrm{COF}$ eigenvalues obtained from ice-core measurements. For both $\mathrm{P}$ and $\mathrm{S}$ waves, a preferred orientation of the ice crystals has an influence on the wave propagation speed. In addition, 
an abrupt change in COF causes partial reflection of propagating wave energy.

A linear relationship exists to calculate the relative dielectric permittivity from the measured eigenvalues (Fujita et al., 2000). Hence, the velocity of the radar wave in anisotropic ice as well as the reflection coefficient can be calculated approximately. In order to calculate seismic velocities and reflection coefficients for different anisotropic ice fabrics, we presented a framework to derive the anisotropic polycrystal elasticity tensor from COF eigenvalues in Part 1 of this work (Diez and Eisen, 2015). We apply this methodology here to calculate seismic velocities from COF eigenvalues measured along the EDML ice core, retrieved at Kohnen Station, Dronning Maud Land, Antarctica (EDML: EPICA Dronning Maud Land; EPICA: European Project for Ice Coring in Antarctica).

In Sect. 2 we introduce the field site and data sets, followed by a short summary of the calculation of the polycrystal elasticity tensor from COF eigenvalues (Part 1: Diez and Eisen, 2015) in Sect. 3. We present results of a vertical seismic profiling (VSP) measurement carried out within the EDML borehole in Sect. 4 and compare the velocity profile derived from the travel times of the direct waves to the velocities we derive from the COF eigenvalues of the EDML ice core. Both velocity profiles show the same velocity trend. However, the absolute velocity values of the COF-based profile depend on the choice of the monocrystal elasticity tensor measured previously by different authors.

The last part (Sect. 5) then focuses on the influence of the anisotropic fabric on the observed reflection signature of seismic and radar waves. We investigate the reflection signals visible in the seismic and radar data from Kohnen Station and compare them to the measured COF eigenvalues to determine COF-induced reflections. This allows us to identify purely conductivity-induced reflections in the radar data, which are layers of equal age and can, thus, be used safely to laterally extrapolate the age of the ice along the reflections.

\section{Field data at Kohnen Station}

Kohnen Station $\left(75^{\circ} 00^{\prime} \mathrm{S}, 00^{\circ} 4^{\prime} \mathrm{E}\right)$ is located on the Antarctic Plateau at an elevation of $2892 \mathrm{~m}$ (WGS84) and some $550 \mathrm{~km}$ south-east of the German overwintering station Neumayer III (Fig. 1). Within the EPICA project an ice core (EDML) was drilled from 2001 to 2006, down to a depth of $2774 \mathrm{~m}$ (Oerter et al., 2009). The overall thickness of the ice was estimated from radar data to be $2782 \pm 10 \mathrm{~m}$ (Oerter et al., 2009).

\subsection{Ice core and radar data}

Measurements of the density and dielectric properties were carried out along the EDML ice core by means of $\gamma$ attenuation profiling (GAP) and dielectrical profiling (DEP),

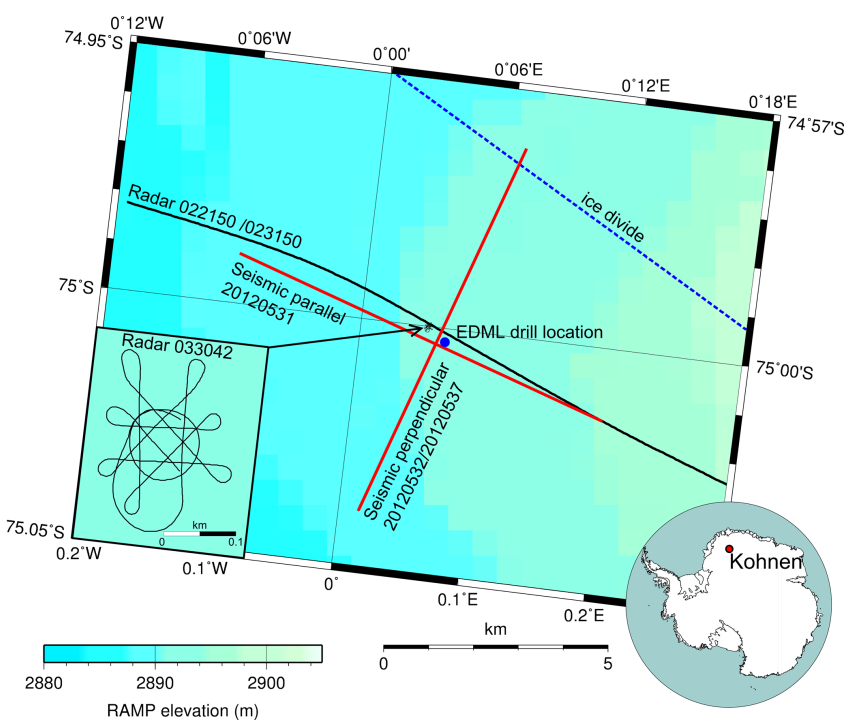

Figure 1. Different surveys carried out at Kohnen Station, Dronning Maud Land, Antarctica (inset of Antarctica "SCAR Antarctica Digital Database"). Geometry of seismic wide-angle survey carried out in January 2012 and 2013, with explosives and vibroseis as the source (red lines). Two lines were shot, one parallel (survey 20120531) and one perpendicular (20120532/20120537) to the ice divide, respectively. The blue dot marks the drill location of the EDML ice core. The flight line of radar survey 022150 (600 ns pulse) and 023150 (60 ns pulse) is plotted in black. The inset shows survey 033042 (60 ns pulse) done with the aircraft taxiing on the ground.

down to a depth of 448 and $2565 \mathrm{~m}$, respectively (Eisen et al., 2006). The temperature in the borehole was measured in 2005 (Wilhelms et al., 2007); temperature logging was repeated in January 2012. The temperature range of -44 to $-7^{\circ} \mathrm{C}$ was determined in the undisturbed borehole between 80.05 and $2591.44 \mathrm{~m}$ depth. Grain radius was also re-measured along the ice core in $\sim 10 \mathrm{~m}$ intervals (Binder, 2014) with higher resolution than in previous measurements (Weikusat et al., 2009).

Measurements of COF (Fig. 2a) were carried out along the EDML ice core between 104 and $2563 \mathrm{~m}$ depth (Hamann et al., 2005; Eisen et al., 2007). After the ice core was stored at $-30^{\circ} \mathrm{C}$, the $c$ axes' distribution was determined in 2005 on horizontal $(0.5 \mathrm{~mm} \times 50 \mathrm{~mm} \times 50 \mathrm{~mm})$ and vertical $(0.5 \mathrm{~mm} \times 50 \mathrm{~mm} \times 100 \mathrm{~mm})$ thin sections using an automatic fabric analyser. The sampling interval was mostly $\sim 50 \mathrm{~m}$, with some regions of denser sampling of $\sim 10 \mathrm{~m}$ in the deeper part of the ice core. The derived eigenvalues from the horizontal and vertical sections show some variations within \pm 0.1 , which are attributed to the cutting of the samples and, thus, exclusion of certain grains (Eisen et al., 2007; Drews et al., 2013). Statistical weighting was done per grain for the calculation of the COF eigenvalues. The results show cone fabrics developed to various degrees in the upper 

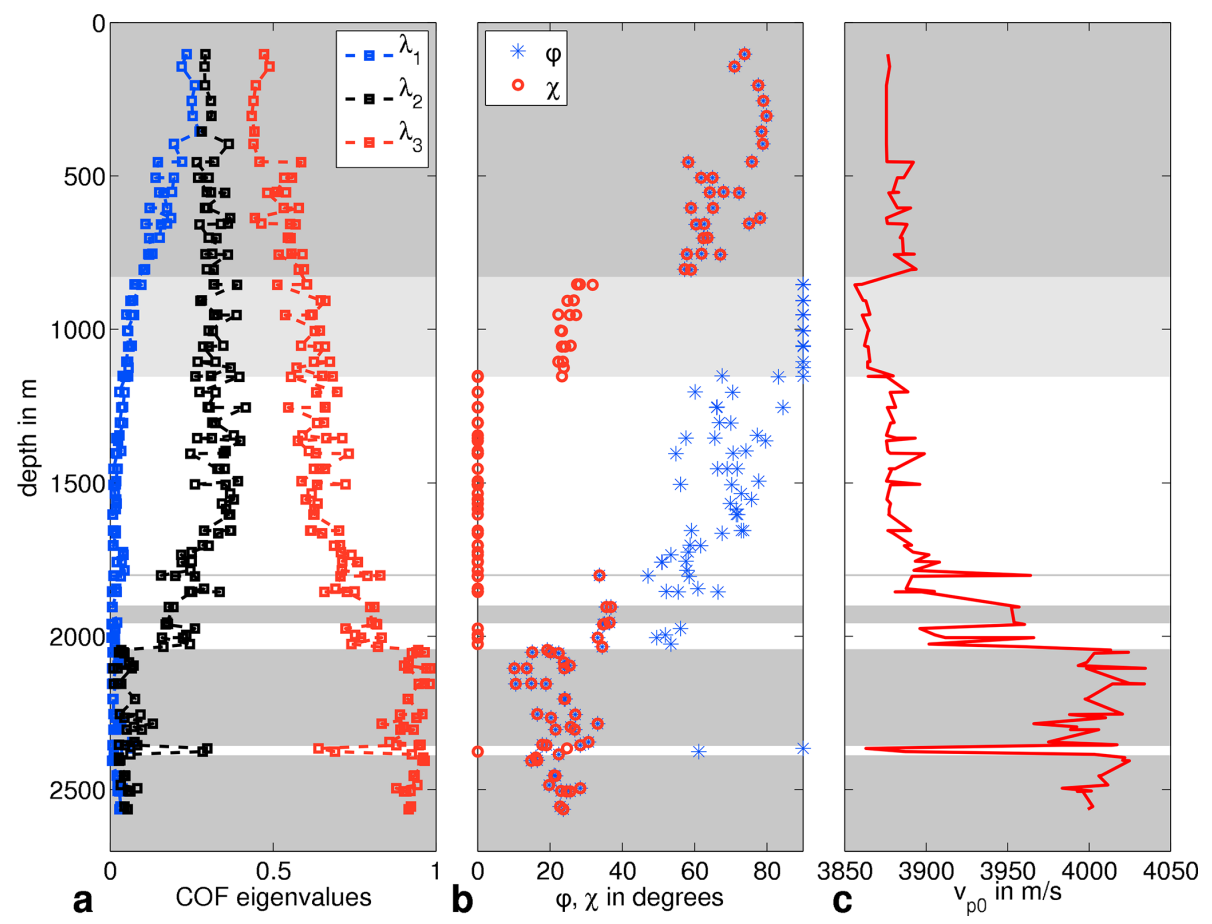

Figure 2. (a) COF eigenvalues derived from the orientation tensor measured on thin sections of the ice core EDML. (b) Opening angles derived from the eigenvalues in (a). Dark grey regions with $\varphi=\chi$ contain cone fabrics, light-grey regions with $\varphi=90^{\circ}$ contain thick girdle fabrics and white regions with $\chi=0^{\circ}$ contain partial girdle fabric. (c) Zero-offset P-wave velocity $v_{\mathrm{p} 0}$ calculated from the elasticity tensors derived from the opening angles in (b).

and lower part of the ice sheet and different girdle distributions within.

Radar data sets from the region (Fig. 1) include profiles with 60 and $600 \mathrm{~ns}$ pulse (profile 023150/022150) recorded during flight with the AWI (Alfred Wegener Institute) research aircraft Polar 2. Additionally, a survey was carried out with the aircraft taxiing on the ground in a circle with a radius of about $50 \mathrm{~m}$ and six legs crossing the circle in different directions using a $60 \mathrm{~ns}$ pulse (profile 033042, Fig. 1, inset).

The radar measurements, in combination with the COF measurements, were used in a study by Eisen et al. (2007) to reveal a strong radar reflector at $2035 \mathrm{~m}$ depth caused by a transition of girdle fabric distribution to a narrow cone fabric distribution. Drews et al. (2013) attributed a change in the azimuthal radar backscatter over depth to a change in $\mathrm{COF}$ variability. Both Eisen et al. (2007) and Drews et al. (2013) concluded from the observed reflection pattern an orientation of the girdle fabric parallel to the ice divide.

\subsection{Seismic measurements}

Seismic measurements close to the drill site of the EDML ice core were carried out in January 2012 and 2013. The measurements included a VSP and wide-angle surveys. For data recording, three-component (3C) geophones as well as a streamer and a borehole geophone were used. We carried out explosive and vibroseis surveys. For the explosive sur- veys we used booster as well as denotation cord charges. Vibroseis surveys employed the micro-vibrator ElViS and the $12 \mathrm{t}$ vibrator system EnviroVibe (IVI, USA) with a peak force of $66 \mathrm{kN}$ (Eisen et al., 2014). Here we present results of the VSP survey as well as the wide-angle survey with explosive sources.

For the VSP measurement a single-borehole geophone was lowered to a depth of $2580 \mathrm{~m}$ in the liquid-filled borehole. Shooting the VSP data set was done in two steps. First, $10 \mathrm{~m}$ of detonation cord $\left(10 \mathrm{~g} \mathrm{~m}^{-1}\right.$ pentolite, survey 20120545) was used as a coiled-up source, always at the same location on the surface. The borehole geophone was pulled upwards from 2580 to $100 \mathrm{~m}$ depth in $40 \mathrm{~m}$ intervals. A day later the same measurement was carried out with boosters (150 g pentolite, survey 20120546) as the source on the same location as the detonation cord, but in a depth interval between 2560 and $1600 \mathrm{~m}$, again in $40 \mathrm{~m}$ steps. By combining both measurements, the depth intervals below $1600 \mathrm{~m}$ were effectively reduced to $20 \mathrm{~m}$ intervals. The depth provided here is given with respect to the top of the borehole casing, which was $13.5 \mathrm{~m}$ below the January 2012 surface. The shot location at the surface was $30 \mathrm{~m}$ away from the borehole towards the south-south-east (Fig. 3). For data recording, Geodes (Geometrics Inc., USA) were used, with a sample interval of $0.25 \mathrm{~ms}$ and a record length of $5 \mathrm{~s}$. During VSP recording the generator of the close-by Kohnen Station was 


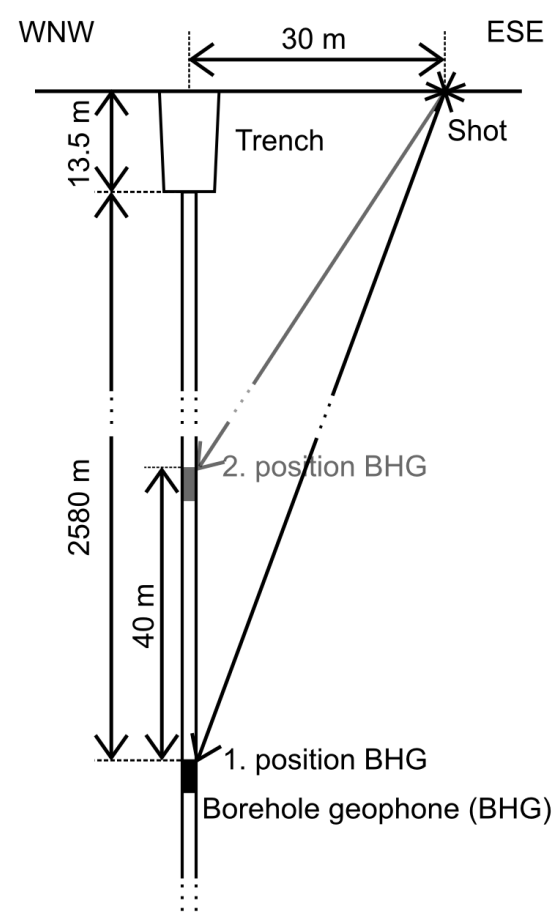

Figure 3. Geometry for shooting of VSP survey. The shot location was $30 \mathrm{~m}$ away from the borehole location. The borehole geophone (BHG) was pulled up in intervals of $40 \mathrm{~m}$ from a depth of 2580 to $60 \mathrm{~m}$ depth for the detonation cord as the source. The survey was complemented between 2560 and $1600 \mathrm{~m}$, with boosters as the source and locations of the borehole geophone shifted by $20 \mathrm{~m}$ to the previous survey, likewise in $40 \mathrm{~m}$ intervals. The depth is given to the top of the borehole casing, measured to be $13.5 \mathrm{~m}$ below the surface (January 2012).

always disconnected from the Kohnen power supply grid to avoid strong electric, $50 \mathrm{~Hz}$ generator-produced noise.

Concurrent with the operation of the borehole geophone a line of $243 \mathrm{C}$ geophones, at $5 \mathrm{~m}$ increments, was placed between 100 and $215 \mathrm{~m}$ south of the shot. Borehole and $3 \mathrm{C}$ geophone data were recorded with a sample interval of $0.25 \mathrm{~ms}$ and a record length of $5 \mathrm{~s}$ on the same Geodes. The $3 \mathrm{C}$ data were used to evaluate the reproducibility of different shots and compare the quality of the detonation cord and booster survey.

Adjacent to the VSP measurement wide-angle surveys were carried out (Fig. 1) parallel (survey 20120531) and perpendicular (survey 20120532/20120537) to the ice divide, with explosive as well as vibroseis sources. For the recording we used a 60-channel snow streamer with a total spread of $1475 \mathrm{~m}$ and $25 \mathrm{~m}$ channel spacing. Each channel consists of eight geophones. For the recording of the different surveys, Geodes as well as the StrataView acquisition systems were used.

The wide-angle data sets were processed with the focus on analysing englacial reflectors. After processing it was not possible to clearly identify englacial signals within the shot gathers; hence, we used the velocities determined during the VSP survey to carry out a normal-moveout correction. We then stacked 60 traces of each available shot, assuming that englacial layer boundaries are surface parallel and laterally homogeneous. This significantly improved the signal-to-noise ratio, allowing the identification of englacial reflection events. The clearest signals could be observed in data from an explosive shot (5.6 kg pentolite) that was carried out in a $30 \mathrm{~m}$ deep borehole (20120537). This shot shows the highest-frequency content and the least amount of disturbing surface waves. We will use this stacked trace for comparison of seismic, radar and ice-core data in Sect. 5.

\section{Calculation of seismic velocities for anisotropic ice}

We briefly summarize our approach introduced in Part 1 of this work (Diez and Eisen, 2015) to calculate seismic velocities from the $\mathrm{COF}$ eigenvalues. As a first step we distinguish between different fabrics based on the COF eigenvalues and calculate two opening angles, $\varphi$ and $\chi$. The opening angles give the extent of the envelope of the $c$ axes' distribution. One of the opening angles is already determined by the fabric classification, for which we distinguish between cone fabrics $(\varphi=\chi)$, thick girdle $\left(\varphi=90^{\circ}, \chi\right)$ and partial girdle fabrics $\left(\chi=0^{\circ}, \varphi\right)$. The elasticity tensor of the polycrystal is then calculated by integrating a measured elasticity tensor with a normal density distribution using these opening angles (Part 1: Diez and Eisen, 2015).

Elasticity tensors of ice were measured previously by different authors, by means of a range of methods, including Brillouin spectroscopy, ultrasonic sounding, the SchaeferBregmann method or the analysis of resonance frequencies. These different elasticity tensors are listed in Table 1 . The measured elasticity tensors are used here to calculate the anisotropic polycrystal elasticity tensor for the different fabrics and, from these, seismic velocities. Different, exact and approximate solutions exist for the calculation of phase and group velocities for different anisotropic fabrics. Here, we use the equations derived by Daley and Krebes (2004) for the calculation of phase velocities for orthorhombic media (Part 1: Diez and Eisen, 2015).

Applying this approach to the COF eigenvalue data of the EDML ice core (Fig. 2a), we find the following classifications for the $c$ axis fabrics (Fig. 2b). Down to a depth of $450 \mathrm{~m}$ a cone fabric with large opening angles $(\varphi=\chi \geq$ $70^{\circ}$ ) is derived from the eigenvalues, i.e. a fabric close to isotropic. At this depth the eigenvalues show a distinct jump to a more anisotropic fabric. Here, we obtain a cone fabric with opening angles between 55 and $80^{\circ}$. At the depth of $800 \mathrm{~m}$ a change to a thick girdle fabric follows. The eigenvalues show larger variations in the eigenvalues $\lambda_{2}$ and $\lambda_{3}$ from this depth downwards. Nevertheless, this change in the eigenvalues of $\lambda_{2}$ and $\lambda_{3}$ is a gradual change, not a distinct jump in the available resolution of COF data. Below $1150 \mathrm{~m}$ 
Table 1. Different measured elasticity tensors and the calculated elasticity tensor of Penny (1948) (all values in $10^{9} \mathrm{~N} \mathrm{~m}^{-2}$ ). The order follows later calculations of the P-wave velocities from lower to higher velocities using the given elasticity values. The second part of the table gives the root-mean-square (rms) error in $\mathrm{m} \mathrm{s}^{-1}$ calculated from the VSP interval velocities derived from first break (fb), maximum ( $\max$ ) and zero-crossing (zc) picks in comparison to the EDML interval velocities derived from the COF eigenvalues. The smallest rms errors are in bold font.

\begin{tabular}{|c|c|c|c|c|c|c|c|c|}
\hline & \multicolumn{5}{|c|}{ Elasticity tensor } & \multicolumn{3}{|c|}{ rms error } \\
\hline & $C_{11}$ & $C_{33}$ & $C_{55}$ & $C_{12}$ & $C_{13}$ & $\mathrm{fb}$ & $\max$ & $\mathrm{zc}$ \\
\hline Bass et al. (1957) & $13.3 \pm 0.8$ & $14.2 \pm 0.7$ & $3.06 \pm 0.015$ & $6.3 \pm 0.8$ & $4.6 \pm 0.9$ & 147 & 160 & 155 \\
\hline Green and Mackinnen (1956) & $13.33 \pm 1.98$ & $14.28 \pm 0.54$ & $3.26 \pm 0.08$ & $6.03 \pm 0.72$ & $5.08 \pm 0.72$ & 115 & 125 & 121 \\
\hline Dantl (1968) & $13.21 \pm 0.04$ & $14.43 \pm 0.06$ & $2.89 \pm 0.02$ & $6.7 \pm 0.13$ & $5.79 \pm 0.41$ & 106 & 117 & 112 \\
\hline Brockamp and Querfurth (1964) & 13.63 & 14.85 & 3.04 & 6.69 & $(5.19)$ & 79 & 87 & 83 \\
\hline Gammon et al. (1983) & $13.93 \pm 0.04$ & $15.01 \pm 0.05$ & $3.01 \pm 0.01$ & $7.08 \pm 0.04$ & $5.77 \pm 0.02$ & 59 & 61 & 57 \\
\hline Jona and Scherrer (1952) & $13.845 \pm 0.08$ & $14.99 \pm 0.08$ & $3.19 \pm 0.03$ & $7.07 \pm 0.12$ & $5.81 \pm 0.16$ & 58 & 57 & 54 \\
\hline Bennett (1968) & $14.06 \pm 0.08$ & $15.24 \pm 0.12$ & $3.06 \pm 0.03$ & $7.15 \pm 0.15$ & $5.88 \pm 0.25$ & 62 & 53 & 52 \\
\hline Penny (1948) & 15.2 & 16.2 & 3.2 & 8 & 7 & 171 & 155 & 159 \\
\hline
\end{tabular}

depth a partial girdle fabric can be observed with opening angle $\varphi$ decreasing with depth and the onset of a cone fabric with opening angles around $35^{\circ}$ at $1800 \mathrm{~m}$ depth, interrupted by thin regions of partial girdle fabric. A strong cone fabric with opening angles between 10 and $33^{\circ}$ is observed below $2040 \mathrm{~m}$, interrupted by a thin $(\sim 30 \mathrm{~m})$ layer of girdle fabric.

Figure $2 \mathrm{c}$ shows as an example the zero-offset P-wave velocity $v_{\mathrm{p} 0}$ calculated from the monocrystal elasticity tensor measured by Gammon et al. (1983) converted to the polycrystal elasticity tensor and seismic velocities with our method mentioned above. In the following and if not stated differently, we always use the elasticity tensor measured by Gammon et al. (1983) for our calculation. In the upper $450 \mathrm{~m}$ we determine velocities of about $3870 \mathrm{~m} \mathrm{~s}^{-1}$ with only minor variations, followed by slightly higher velocities, up to $3890 \mathrm{~m} \mathrm{~s}^{-1}$, and a change to lower velocities down to $3860 \mathrm{~m} \mathrm{~s}^{-1}$ again at $850 \mathrm{~m}$ depth. Below $1800 \mathrm{~m}$ depth the zero-offset velocity starts to increase with the stronger orientation of the $c$ axes towards the vertical. Corresponding to the change in the COF eigenvalues at $2040 \mathrm{~m}$ depth, they reach a velocity of around $4010 \mathrm{~m} \mathrm{~s}^{-1}$. We use this zero-offset Pwave velocity $v_{\mathrm{p} 0}$ profile, from now on called EDML interval velocities, for later comparison with the velocity profile derived from the VSP measurement. These jumps in velocity of $16 \mathrm{~m} \mathrm{~s}^{-1}$ at $450 \mathrm{~m}$ depth and of $30 \mathrm{~m} \mathrm{~s}^{-1}$ at $800 \mathrm{~m}$ depth are caused by the classification into the different fabrics needed for the calculation of the opening angles. As discussed in Part 1 (Diez and Eisen, 2015) we need to classify the eigenvalues into different groups to be able to calculate the elasticity tensor. Thus, artificial velocity steps are introduced. Possibilities to overcome this problem include the calculation of opening angels directly from the information of the $c$ axis orientation or by using the orientation distribution function (Part 1: Diez and Eisen, 2015). It is important to keep these artificial velocity jumps in mind when analysing the velocity profile or calculating reflection coefficients. However, to enable direct applicability of our method to existing ice-core data sets, normally describing the crystal orientation using the COF eigenvalues, we except this limitations of our approach for the sake of ease of use.

\section{Vertical seismic profiling (VSP)}

A VSP survey has the advantage that the wave velocities can be calculated directly from the travel times due to the known depth, in contrast to reflection seismic profiles where the depth of the layer is often unknown. By comparing velocities determined from the VSP survey and the COF eigenvalues, we want to find out if absolute values and variations observed in either method match. This provides a general evaluation of the approaches and of the travel-time-depth conversion for locations of englacial seismic reflector depths.

The VSP data show clear signals from the direct wave (Fig. 4) travelling from the shot at the surface to the geophone within the borehole (Fig. 3). The detonation cord survey (survey 20120545, Fig. 4a) has a well-defined onset of the first break. Greater variations can be observed in the booster data (survey 20120546, Fig. 4b). Strong noise is visible in most of the booster shots for travel times $\leq 0.2 \mathrm{~s}$. For shot 11 the trigger obviously did not work correctly, and in the case of shot 14 strong noise throughout the record is visible, making it difficult to pick the signal of the direct wave.

We evaluate the variability of repeated explosive shots with the same charge size at the same location with the simultaneously recorded data from the $3 \mathrm{C}$ geophones. For each shot the data of the vertical component of the geophone closest to the borehole are shown in Fig. 5. For the detonation cord survey (Fig. 5a) the first nine shots are very similar; afterwards the shape of the wavelets becomes significantly more variable and the arrival times have variations of up to $1 \mathrm{~ms}$. In the case of the boosters as the source (Fig. 5b), variations are altogether larger with differences in the arrival time 


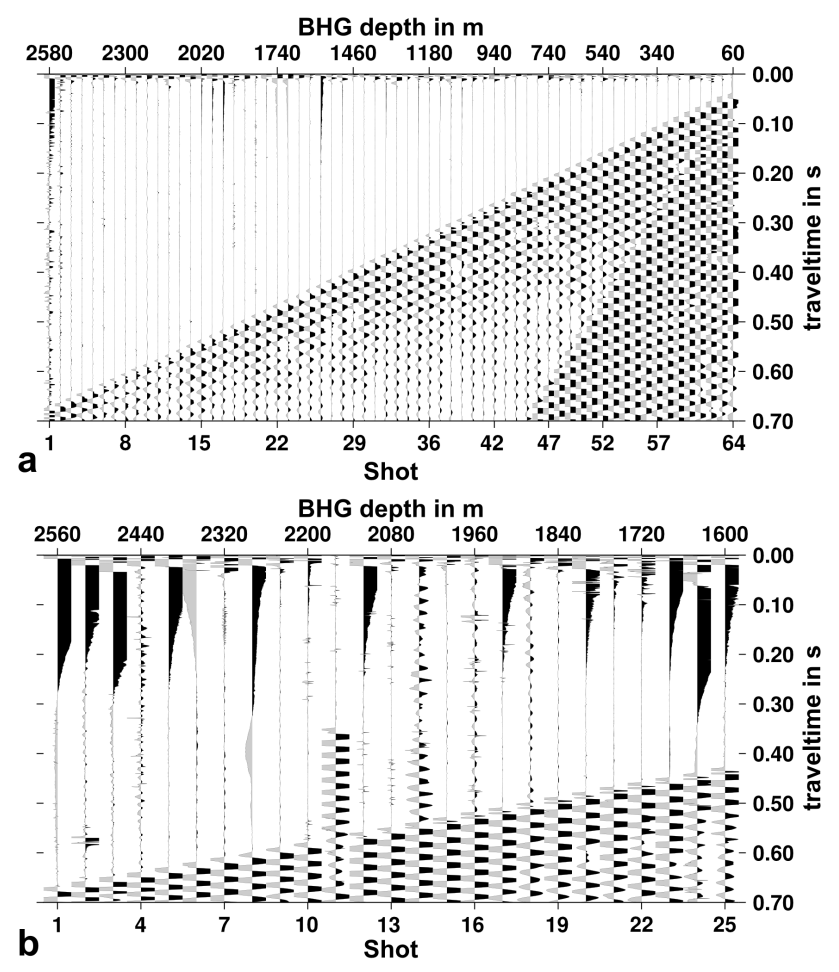

Figure 4. Recorded first arrivals from the VSP surveys with detonation cord (a, survey 20130545) and booster (b, survey 20130546) as the source. The top ordinate gives the location and, hence, the depth of the borehole geophone (BHG); the bottom ordinate shows the shot number. In (a) not only the direct $\mathrm{P}$-wave arrival is visible but also a borehole-guided wave travelling with a velocity of $1150 \mathrm{~m} \mathrm{~s}^{-1}$. Depth is given here to top of casing.

of up to $2 \mathrm{~ms}$. Repeated shooting at the same point produced a hole of $\sim 1 \mathrm{~m}$ depth over time. This might have changed the characteristics of the first break of the wavelet, causing the variations in arrival time.

We picked the travel time of every shot of the VSP survey with detonation cord and boosters to determine seismic velocity variations with depth. The data were resampled from $0.25 \mathrm{~ms}$ recording interval to $0.125 \mathrm{~ms}$ for a more precise picking of the first arrivals. Resampling was done with the seismic processing package ECHOS by a four-point interpolation filter. Some of the picks were corrected due to distinct changes in the travel time observed in the data of the $3 \mathrm{C}$ geophones (Fig. 5), for example as visible for shot 44 of the detonation cord survey. To reduce the picking error, the first break (fb), the first maximum (max) and the first zero crossing (zc) of the direct arrival were picked. This was done by two different persons to obtain statistical picking uncertainty.

From the picked travel times the interval velocities were calculated for the $40 \mathrm{~m}$ depth intervals between shots separately for the detonation cord and booster survey as well as for the different picks. Due to the shooting geometry (Fig. 3) the difference in travel path from one shot to the next with
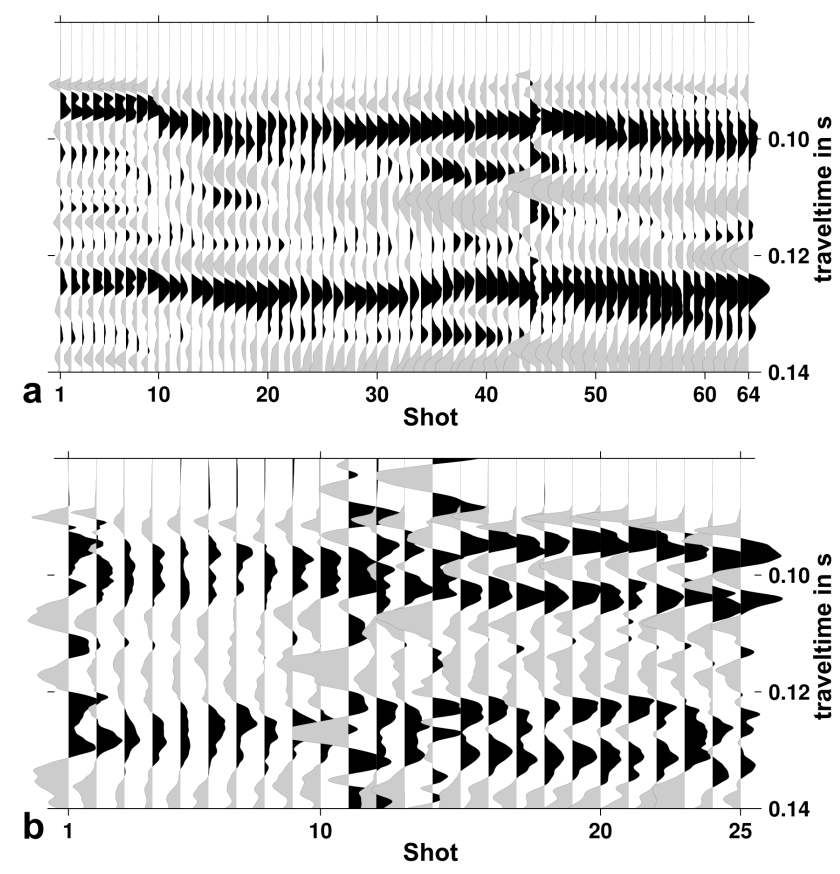

Figure 5. Traces of the vertical component of the $3 \mathrm{C}$ geophone on the surface, $100 \mathrm{~m}$ away from the shot location, during the VSP survey with the detonation cord (a) and booster (b) as the source.

the geophone at different depths is equal to or smaller than the vertical geophone distance of $40 \mathrm{~m}$. For the calculation of the interval velocities the difference in the travel paths was used rather than the difference in borehole geophone depth. However, a straight travel path was assumed and refractions in the firn were neglected. The difference in travel path for a straight-ray path compared to a curved-ray path is $4 \mathrm{~cm}$ between the uppermost geophone positions at 100 and $140 \mathrm{~m}$ depth, decreasing for deeper depth intervals. Hence, the error is $\leq 0.1 \%$ and is regarded as negligible considering the accuracy of the obtainable borehole position within the trench the borehole geophone position at depth and the accuracy in picking travel times. Further corrections were applied due to the elongation of the rope, which has an effect on the mean velocity. However, this effect is basically negligible for the interval velocities.

Joint analysis of the interval velocities derived from different picks of the wavelet (fb, max, zc) is only valid if the wavelet does not significantly change over depth due to, e.g., dispersion or frequency-dependent attenuation. For an unchanged wavelet shape over depth the travel time difference between the picked maximum and the first break $[\max -\mathrm{fb}]$, as well as the zero crossing and the first break $[\mathrm{zc}-\mathrm{fb}]$, should be constant. However, the travel time differences, i.e. the frequencies of the wavelet we observe, are not constant over depth and, hence, not independent of dispersion or frequency-dependent attenuation. While we observe an increase in frequency with increasing depth (and thus later 


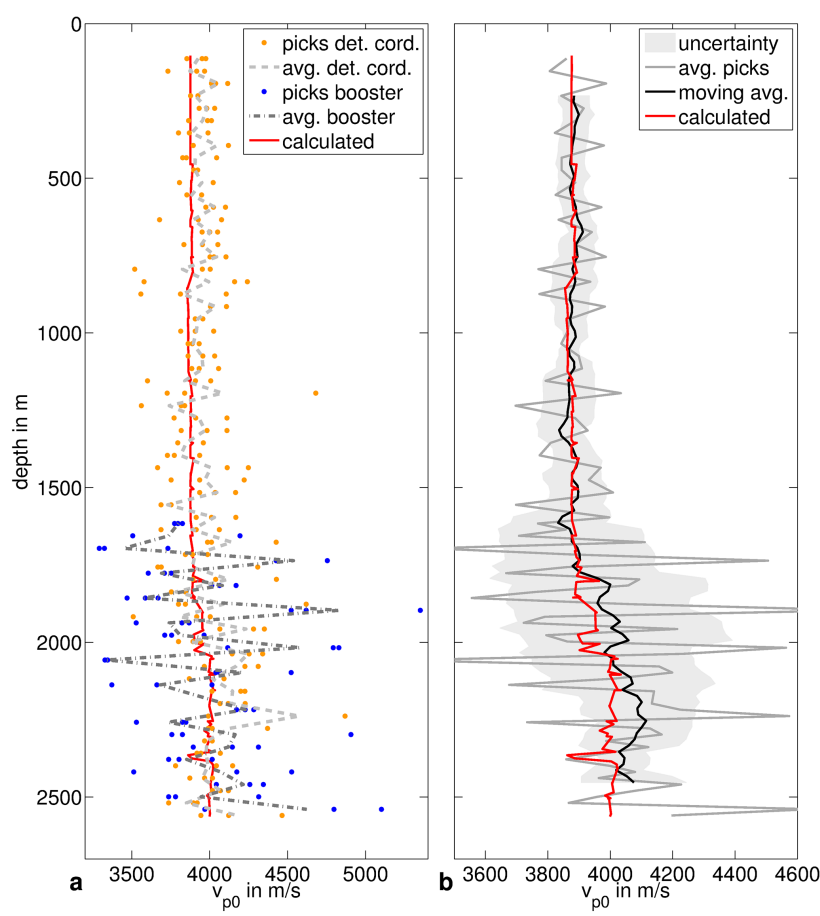

Figure 6. (a) The picked interval velocities for first break, maximum and zero crossing picked from the detonation cord survey (orange dots) and the booster survey (blue dots) with the corresponding average, dashed light-grey line (detonation cord) and dasheddotted line (booster). (b) Average interval velocity (grey line) derived from the travel times of the detonation cord and booster survey for the three different picks (first break, maximum, zero crossing). The black line shows the moving average with a sliding window of $200 \mathrm{~m}$ and its rms error (grey area). These interval velocities are temperature-corrected to $-16^{\circ} \mathrm{C}$. The red line in both subfigures shows the $v_{\mathrm{p} 0}$ interval velocity calculated from the COF eigenvalues of the EDML ice core as given in Fig. 2.

shooting times) for the wavelets from the detonation cord survey, we observe a decrease in frequency over depth (and thus later shooting times) for the wavelets from the booster sources. We suggest that this signal trend is an effect of the repeated shooting at the same location rather than an indication of physical properties, like frequency-dependent attenuation.

Finally, to be able to compare the VSP velocities with the velocities calculated from the COF eigenvalues (Fig. 2c), a temperature correction has to be applied. The elasticity tensors of Gammon et al. (1983) were measured at $-16^{\circ} \mathrm{C}$. Hence, we correct the VSP velocities with the gradient for $\mathrm{P}$ waves given by Kohnen (1974) of $-2.3 \mathrm{~m} \mathrm{~s}^{-1} \mathrm{~K}^{-1}$ for the temperatures measured within the EDML borehole (Sect. 2.1). This gives the corrected interval velocities (Fig. 6) of the booster source survey (a, blue dots) and the detonation cord survey (a, orange dots) for the picks from different wavelet regions (fb, max, zc). The dashed-dotted grey line gives the mean over the different picks from the booster survey; the dashed light-grey line shows the average over the different picks from the detonation cord survey. Both surveys are analysed together. Thus, we obtain the interval velocities from the VSP measurements (Fig. 6b, grey line) as a mean of all derived interval velocities of the different sources, i.e. booster (blue dots) and detonation cord (orange dots) averaged from the picks from different wavelet regions (fb, max, zc, each from two different persons).

\subsection{Comparison of VSP and EDML interval velocities}

Larger velocity variations can be observed in the booster data (Fig. 6a, blue dots) compared to the detonation cord data (orange dots). Analysing all picks together, the variations in the VSP interval velocities are still large, with extrema up to 3350 and $4800 \mathrm{~m} \mathrm{~s}^{-1}$ (Fig. 6b, grey line). For improved clarity of the main velocity trend, we apply a $200 \mathrm{~m}$ moving average to the VSP interval velocities (Fig. 6b, black line). The grey area (Fig. 6) shows the root-mean-square (rms) error calculated as the variations of the picked values to this moving average. The rms errors of these averaged VSP interval velocities are rather large, especially in the region between $1600 \mathrm{~m}$ depth and $2200 \mathrm{~m}$ depth. The large error in this region is attributed to the oscillating nature of the velocity results from the booster survey, probably due to incoherent excitation of elastic waves for shots 10 to 25 (Fig. 5b).

The EDML interval velocity and the averaged VSP interval velocities show good agreement above $1800 \mathrm{~m}$ depth, with a velocity around $3870 \mathrm{~m} \mathrm{~s}^{-1}$. In this region cone fabric with large opening angles exist up to $450 \mathrm{~m}$ depth; below girdle structures can be observed (Fig. 2b). The averaged VSP interval velocities show an increase to velocities $\geq 4020 \mathrm{~m} \mathrm{~s}^{-1}$ at $1800 \mathrm{~m}$ depth. Jumps in the calculated EDML interval velocities can also be observed in this region. For the strongly developed cone fabric with small opening angles below $2030 \mathrm{~m}$ depth the averaged VSP and EDML interval velocities agree well again with an average velocity of $\sim 4040 \mathrm{~m} \mathrm{~s}^{-1}$ for the VSP velocities and $\sim 30 \mathrm{~m} \mathrm{~s}^{-1}$ slower for the EDML velocities.

\subsection{Different elasticity tensors}

To evaluate the effect of the different elasticity tensors on calculated $\mathrm{P}$-wave velocities from COF data, the averaged VSP interval velocities determined from first break, maximum and the zero crossing are considered separately in the following comparison (black lines, Fig. 7). We thus avoid including the effect of dispersion. The different elasticity tensors, calculated and measured, are given in Table 1.

The velocity profiles of the different picks (fb, max, zc) show slight variations, but the main trend is the same in all averaged interval velocity profiles. For the first $\sim 800 \mathrm{~m}$, higher velocities can be found for the averaged interval velocities derived from the max and zc picks than for the $\mathrm{fb}$ picks. The VSP interval velocities are corrected for the tem- 


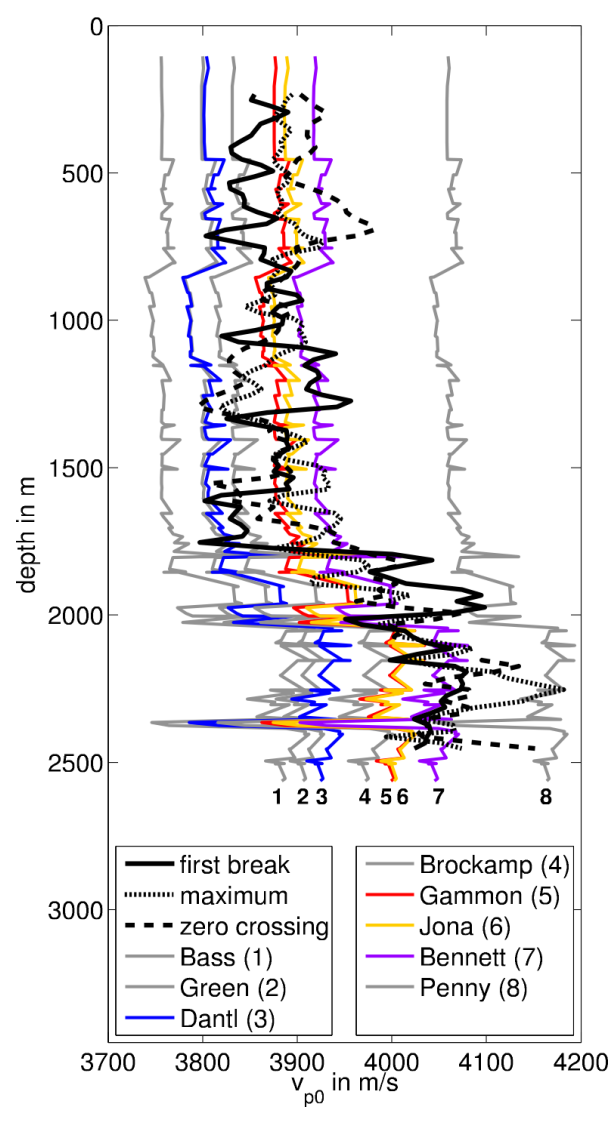

Figure 7. Comparison of vertical $\mathrm{P}$-wave velocities calculated from the EDML eigenvalues with different elasticity tenors (Table 1) with the interval velocities derived from the VSP data sets for the first break, the maximum and the zero crossing (black lines).

perature distribution within the ice sheet to $-16^{\circ} \mathrm{C}$. Additionally, the velocities calculated using the elasticity tensor of Bennett (1968), given at $-10^{\circ} \mathrm{C}$, are corrected to $-16^{\circ} \mathrm{C}$ as well.

The different vertical P-wave velocities calculated from the different elasticity tensors all follow the same velocity trend over depth, which is determined by the COF eigenvalues. The highest $\mathrm{P}$-wave velocities are calculated from the theoretically derived elasticity tensor of Penny (1948), and the lowest derived P-wave velocities from the elasticity tensor of Bass et al. (1957), who used the resonance frequencies to derive the components of the elasticity tensor. The velocities derived from the elasticity tensors of Gammon et al. (1983), Jona and Scherrer (1952) and Bennett (1968) all show good agreement with the VSP velocities.

This result is confirmed by the rms differences that we calculate between the averaged VSP interval velocities from first break, maximum and zero-crossing picks and the EDML interval velocities derived with the different elasticity tensors (Table 1). Keeping the error bars in mind (up to $\pm 350 \mathrm{~m} \mathrm{~s}^{-1}$; Fig. 6, grey area), the velocities derived from the latter three elasticity tensors are all capable of explaining the velocity profile derived from the VSP survey by using the respective COF eigenvalues. The best accordance is gained using the elasticity tensor of Jona and Scherrer (1952). None of the elasticity tensors reach the complete range of minimum and maximum interval velocities $\left(3870-4040 \mathrm{~m} \mathrm{~s}^{-1}\right)$ of the averaged VSP results. While the velocities derived by the Jona and Scherrer (1952) and Gammon et al. (1983) elasticity tensor fit well to the averaged VSP velocities above $1800 \mathrm{~m}$, i.e. for lower velocities of $\sim 3870 \mathrm{~m} \mathrm{~s}^{-1}$, the ones derived from the Bennett (1968) elasticity tensor fit better below $1800 \mathrm{~m}$, for the higher velocities of $\sim 4040 \mathrm{~m} \mathrm{~s}^{-1}$ (Fig. 7). The larger depth interval between 200 and $1800 \mathrm{~m}$ depth compared to the interval between 1800 and $2600 \mathrm{~m}$ depth is the reason why the rms differences for the Gammon et al. (1983) and Jona and Scherrer (1952) elasticity tensor are slightly smaller than those for the Bennett (1968) elasticity tensor.

\subsection{Discussion of VSP survey}

The comparison of the averaged interval velocities from the VSP survey and the interval velocities derived from the COF eigenvalues shows good agreement. The main trend of the VSP velocity profile, $\sim 3870 \mathrm{~m} \mathrm{~s}^{-1}$ above $1800 \mathrm{~m}$ depth, an increase in velocity between 1800 and $2030 \mathrm{~m}$ depth, and $\sim 4040 \mathrm{~m} \mathrm{~s}^{-1}$ below $2030 \mathrm{~m}$, can be reproduced with the calculations of velocities from the COF eigenvalue data.

The averaged interval velocities derived from the VSP survey are compared to the zero-offset velocities calculated from the eigenvalues. As the shots during the survey were carried out on the surface $30 \mathrm{~m}$ away from the drill location of the EDML ice core (Fig. 3), the travel path of the seismic wave is not zero-offset. The first measurement was done at a depth of $100 \mathrm{~m}$. This corresponds to an angle between borehole and travel path of $14.8^{\circ}$, neglecting effects of refraction within the firn. In the anisotropic case the velocity for an incoming angle $\theta$ of $14.8^{\circ}$ differs of course from the zero-offset velocity we use for the comparison. For the existing anisotropy in this depth region, with a cone opening angle $\varphi=\chi \approx 75^{\circ}$, the difference between the zero-offset velocity and the $v_{\mathrm{p}}\left(\theta=14.8^{\circ}\right)$ is $<5 \mathrm{~m} \mathrm{~s}^{-1}$. At the depth of $450 \mathrm{~m}$, where a stronger girdle anisotropy develops, the angle between borehole and wave propagation $\theta$ is already only $3.7^{\circ}$. Thus, the error that is introduced by using the zero-offset EDML interval velocities for the comparison to the VSP interval velocities instead of the velocities corresponding to the actual angle between borehole and travel path during the VSP survey is found to be negligible.

The small-scale variations in the EDML interval velocities reflect the increments of the COF eigenvalues and the classification of these eigenvalues in the different fabrics for the calculation of opening angles. This is especially obvious for the increase in velocity in the region between 1800 and $2030 \mathrm{~m}$ depth, where the narrow cone fabric develops from the girdle fabric. Here, eigenvalues are classified as cone and 
girdle fabric alternately (Part 1: Diez and Eisen, 2015). However, such small-scale variations are averaged out for the frequencies around $100 \mathrm{~Hz}$, as we observe in our VSP survey, and are, therefore, not visible.

In a recent study Gusmeroli et al. (2012) carried out an ultrasonic sounding experiment within the deep borehole at Dome C, East Antarctica, exciting P and SV waves with frequencies of $23 \mathrm{kHz}$. Comparing their picked velocities from the ultrasonic sounding with velocities calculated by averaging the velocity for a vertical single maximum fabric for different incoming angles, as introduced by Bentley (1972), they found the best agreement using the elasticity tensor derived by Dantl (1968). This is in strong contrast with our results, where the velocities derived with the elasticity tensor from Dantl (1968) (Fig. 7, blue line) show a poor fit to the averaged VSP interval velocities (Table 1). Possible reasons for this discrepancy include the methodological difference for velocity calculation and the fact that the samples in this VSP study are determined over significantly larger depth intervals from shot to shot than for the ultrasonic sounding. However, it is more likely that frequencies of 2-orders-ofmagnitude difference are the cause. Unfortunately, we cannot discuss this issue further, as the frequency dependency of seismic wave velocities in ice is not yet fully determined.

\section{Joint interpretation of seismic, radar and ice-core data}

For a better understanding of the origin of laterally coherent englacial seismic and radar reflectors, with a focus on changing COF, we compare these data sets from Kohnen Station (Fig. 1). As a reference we stack 60 traces of one seismic shot to increase the signal-to-noise ratio, without further processing. The normal-moveout correction was done with the velocities derived from the VSP survey. This allows us to identify distinct englacial reflections and directly compare seismic, radar and ice-core data characteristics in the depth domain in the following.

\subsection{Comparison of depth-dependent characteristics}

Five regions are marked A-E in Fig. 8 which contain corresponding signals in at least two of the used data sets from ice-core data (COF eigenvalues and grain radii), the stacked seismic trace and radar data, measured as well as modelled. The given depth was calculated from two-way travel times (TWT) using the VSP velocities in the case of the seismic data and with a constant velocity of $168.7 \mathrm{~m} \mathrm{\mu s}^{-1}$ and a firn correction of $13 \mathrm{~m}$ in the case of the radar data, as justified by Eisen et al. (2006). We do not include a modelled seismic trace in this comparison. The problem is that modelling a seismic trace from the COF eigenvalues with a resolution of around $50 \mathrm{~m}$ causes reflections at the depth where $\mathrm{COF}$ eigenvalues have been measured. This is not necessar- ily at the position of a COF transition, which is likely inadequately resolved. The modelled radar trace was calculated based on high-resolution conductivity measurements. However, the COF information has not been taken into account here, for the above reason.

The radar reflection in region $\mathrm{D}$ was previously attributed to a change in COF (Fig. 8a) from girdle to cone fabric between 2025 and $2045 \mathrm{~m}$ depth by Eisen et al. (2007). Here, a strong signal can be seen in the $600 \mathrm{~ns}$ pulse radar trace (Fig. 8c, blue) as well as in the $60 \mathrm{~ns}$ pulse trace (Fig. 8c, red). Additionally, no corresponding signal can be found in the modelled radar trace (Fig. 8e). The periodic pattern of the traces with different airplane headings (Fig. 8d) indicates an orientation of girdle above cone fabric vertical and parallel to the ice divide (Eisen et al., 2007). This COF-induced radar reflection corresponds to a rather quiet zone within the seismic trace (Fig. 8b), followed by a distinct peak.

Further distinct signals marked $\mathrm{A}$ and $\mathrm{B}$ in the seismic trace correspond to clear signals in the radar data. The strongest seismic reflector is signal B. For both events strong reflections are visible within the $600 \mathrm{~ns}$ radar pulse (Fig. 8c, blue) and a clear signal in the $60 \mathrm{~ns}$ radar pulse (Fig. $8 \mathrm{c}$, red). No prominent signal can be observed in the modelled radar trace based on DEP measurements (Fig. 8e). Whether the radar signal differs for different airplane headings (Fig. 8d) is difficult to judge for event A due to strong noise. In the case of event $\mathrm{B}$ the reflection is also clearly visible on the radar traces for the different airplane headings (Fig. 8d). Clear signals can be observed for headings in E, SE, W and NW directions, and weaker reflections for the remaining directions. A pattern can be recognized in this reflection behaviour but not as clear as the pattern of event D. A jump in the COF eigenvalues (Fig. 8a) $\lambda_{2}$ and $\lambda_{3}$ can be observed over a very short depth interval at event B. In contrast, no variation in the $\mathrm{COF}$ eigenvalues can be observed in the region of event $\mathrm{A}$. The grain radius data show a gradual change towards smaller grains at event A and towards larger grains at event B.

Event $\mathrm{C}$ shows a clear signal in the seismic trace, in strength similar to that of event $\mathrm{D}$. The grain size for both event $\mathrm{C}$ and $\mathrm{D}$ shows a variation of the grain radius of $\sim 0.4-0.7 \mathrm{~mm}$. However, at event $\mathrm{C}$ no clear signal can be observed in the radar data. In contrast, this is an extremely quiet zone within the trace of the $600 \mathrm{~ns}$ pulse (Fig. 8c, blue).

The deepest marked event (event E) at a depth of $\sim 2350 \mathrm{~m}$ corresponds to a $50 \mathrm{~m}$ thick layer of girdle fabric within a region of strongly developed cone fabric visible in the COF eigenvalues (Fig. 8a). A distinct change towards smaller grain radii can be observed in this region. A very small increase in reflection power near the noise floor seems to be observable on the $600 \mathrm{~ns}$ pulse (Fig. 8c, blue). However, no clear radar events are discernible in this depth range. In the seismic data a quiet zone is followed by a signal at the depth of $\sim 2350 \mathrm{~m}$, the transition of the girdle fabric back to cone fabric. 


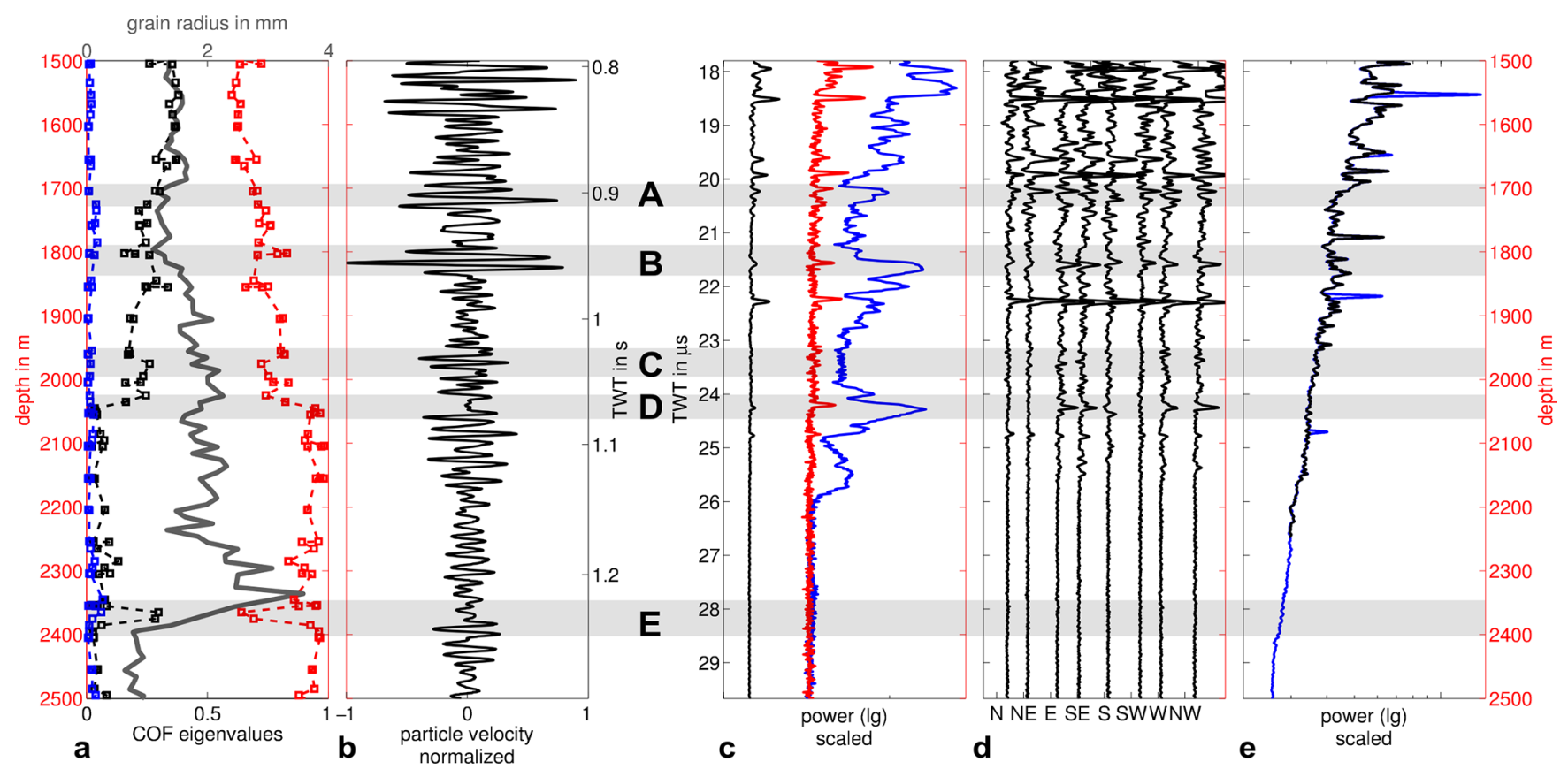

Figure 8. Comparison of (a) ice-core COF eigenvalues and grain radius $r$ (diameter $d=2 r$ ), (b) with a stacked seismic trace of survey 20120537, (c, d) radar data and (e) modelled (synthetic) radar data. (c) shows the radar traces closest to the EDML drill location from survey 022150 (600 ns pulse) in blue and 023150 (60 ns pulse) in red, together with a stack of all traces of survey 033042 (60 ns pulse) in black. (d) shows stacked traces of survey 033042 for different airplane headings, i.e. different polarizations (Fig. 1). (e) is a forwardmodelled radar trace from DEP measurements with (blue) and without (black) conductivity peaks (Eisen et al., 2007). All figures are plotted over depth (red axis), with the two-way travel time on the seismic and radar traces additionally marked (black axis). The marked events A-E are discussed in the text.

\subsection{Interpretation of englacial reflections}

We interpret the reflectors in the radar data at $1690 \mathrm{~m}$ (event A) and $1810 \mathrm{~m}$ depth (event B) as being induced by changing $\mathrm{COF}$, although no clear signals are observable in the COF eigenvalues. However, clear signals can be observed within the seismic and radar trace for both events. The COF eigenvalues in this region were measured with a resolution of $\sim 50 \mathrm{~m}$. This resolution is not fine enough to show distinct changes over sub-wavelength scales (several metres to tens of metres) that can cause reflections in the seismic and radar data. As expected, both events show no corresponding signal in the modelled radar trace.

To estimate the strength of the reflectors from changing physical properties across the interface boundaries caused by the measured COF values, we calculate the theoretical reflection coefficient for normal incidence, $R(0)$. We assume two semi-infinite half-spaces with the derived velocities with zero offset and use the Zoeppritz equation for the calculation of the reflection coefficient (e.g. Aki and Richards, 2002). The change in the COF eigenvalues corresponds to reflection coefficient of $\left.R(0)\right|_{\mathrm{B}}=0.009$ for event $\mathrm{B},\left.R(0)\right|_{\mathrm{C}}=-0.006$ for event $\mathrm{C}$ and $\left.R(0)\right|_{\mathrm{D}}=0.014$ for event $\mathrm{D}$. The reflection coefficient for the interfaces of event $\mathrm{B}$ and $\mathrm{C}$ are 2 orders of magnitude smaller than those of the ice-bed transition (Part 1: Diez and Eisen, 2015).

The seismic reflection amplitude (Fig. 8b) of event $\mathrm{C}$ is significantly weaker than that of event $\mathrm{B}$. Despite the difference of some $30 \%$ in the calculated reflection coefficients, this is inadequate to explain the observed difference in the reflection amplitude. Even if geometrical spreading and attenuation are taken into account for event $\mathrm{C}$, which is $\sim 150 \mathrm{~m}$ deeper than $\mathrm{B}$, the observed difference in reflection amplitude cannot be fully accounted for. Reasons might be that either the true change in anisotropy for event B is larger than that resolved with the coarse eigenvalue measurements or that destructive interference occurs for event $\mathrm{C}$.

In the seismic trace of event $\mathrm{D}$ a quiet zone is followed by a reflection about the same strength as that of event $\mathrm{C}$; also the calculated reflection coefficient is twice as large. Concurrently, the COF eigenvalues change over a depth interval of $20 \mathrm{~m}$. With maximum frequencies around $200 \mathrm{~Hz}$ the seismic data have a maximum vertical resolution of $\sim 10 \mathrm{~m}$. Thus, the transition from girdle to cone fabric over $20 \mathrm{~m}$ depth might be too gradual to cause a corresponding reflection. Another possibility might be that the observed change in eigenvalues is not an isolated transition, but several of these occur, causing partly destructive interference of the seismic wave. This could also explain the quiet zone above the reflection at this 

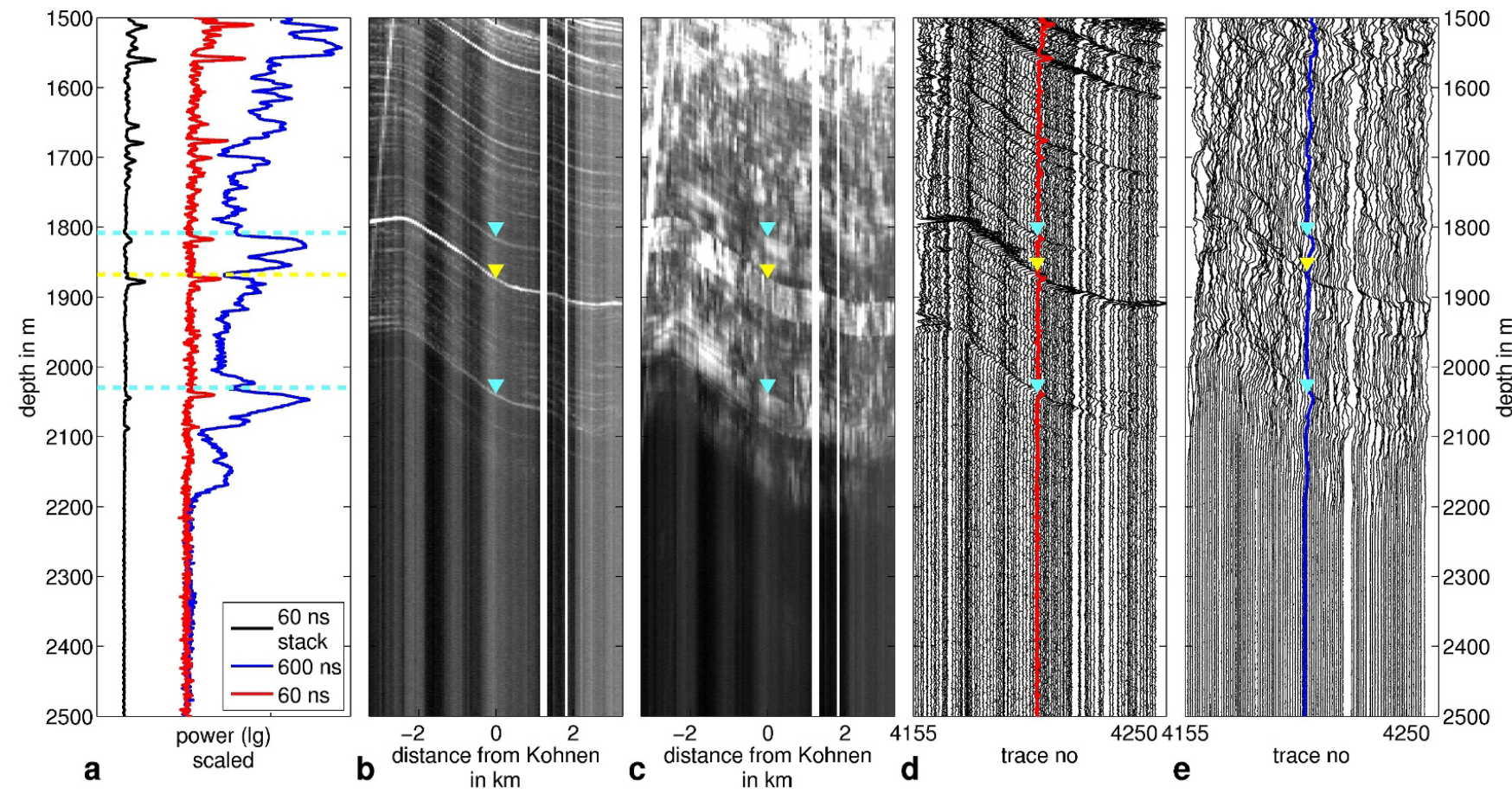

Figure 9. Radar data from Kohnen Station with 60 ns pulse (023150) and 600 ns pulse (022150) as density plot (b and c, respectively) and wiggle plot (d and e, respectively). Subfigure (a) shows the trace closest to the EDML drill location of the $60 \mathrm{~ns}$ pulse (red) and $600 \mathrm{~ns}$ pulse (blue) survey, as well as the stack of all traces of survey 033042 (same figure as Fig 8, c). TWT-depth conversion as in Fig. 8 . The light-blue triangle and lines indicate COF-induced reflections (event B and D from Fig. 8), whereas the yellow triangles and line show a conductivity-induced reflection (likely the Toba event at $74 \mathrm{ka}$ ) for comparison.

depth. The strength of the reflection signal is further influenced by seismic trace stacking. Although this enhances the signal-to-noise ratio in general, it might also weaken some reflections, especially those from dipping reflectors as observed in the radar section (Fig. 9).

A similar effect can be observed at event E. The $50 \mathrm{~m}$ thick layer of developed girdle fabric is visible in the COF eigenvalue data. This corresponds to a quiet zone followed by a clear reflection in the seismic data. The depth of this reflection fits to the transition back from girdle to cone fabric. In contrast, no clear signal can be observed for the transition from cone to girdle fabric $20 \mathrm{~m}$ above. This could be explained by a more gradual change from cone to girdle fabric, while the transition from girdle to cone fabric occurs over a relatively sharp boundary. A second explanation is again the potentially destructive interference of signals from the upper and lower transitions.

For event $\mathrm{E}$, in addition to the variation in the COF eigenvalues a strong change can be observed in the grain radius. This raises the question of whether grain size determines the seismic reflectivity causally, too, or whether this is merely a coincidence. In comparison, the changes in the grain radii are not large for events A to D. Most notably in the case of events $\mathrm{A}$ and $\mathrm{B}$, clear seismic and radar reflectors are observable, while the variations in grain radius are not signifi- cant. The observed variation in the VSP velocities (Sect. 4) argues as well against a dependency of seismic wave propagation primarily on grain size. The grain size increases continuously to about $2350 \mathrm{~m}$ depth, where it decreases significantly (Fig. 8a, grey curve). If changes in the seismic velocity directly depended on grain size, we would expect a decrease in seismic velocities below $2350 \mathrm{~m}$ to values like those observed in the upper part of the ice sheet (above $500 \mathrm{~m}$ depth) where grain size is comparable. This is not the case (Fig. 6). Hence, we argue that the main cause for variations of seismic wave propagation is variations in the crystal orientation. However, we do not exclude the possibility that sudden changes in COF and grain size might be causally linked to the same underlying ice properties, such as impurity content (Gow and Meese, 2007). This link could significantly change the impact of strain-induced boundary migration recrystallization, which controls grain size and COF as observable at almost all depths of the EDML ice core (Weikusat et al., 2009), especially if nucleation sets in, like present in the deepest part (Faria et al., 2014).

\subsection{Lateral coherency of COF-induced reflections}

Our above investigation identified several reflections in seismic and radar data caused by changes in COF. Hence, we are able to evaluate the lateral coherency of these radar hori- 
zons in comparison to radar horizons caused by changes in conductivity. Figure 9 shows extended parts of radar surveys 023150 (60 ns pulse; $b$ and $d$ ) and 022150 (600 ns pulse; $\mathrm{c}$ and e) with straight flight direction. Marked with light-blue triangles and a light-blue line are the two COF reflectors of Fig. 8, event B $(\sim 1800 \mathrm{~m})$ and event D $(\sim 2035 \mathrm{~m})$. The yellow triangles and yellow line mark the conductivity-induced reflection (Eisen et al., 2006), most likely caused by the Toba volcanic eruption about $74 \mathrm{ka}$ (Svensson et al., 2013).

In the single radar trace 4205 (Fig. 9a, red), closest to the EDML drill site, the conductivity-induced reflection is the strongest signal below $1700 \mathrm{~m}$ depth in the $60 \mathrm{~ns}$ pulse data, i.e. the data with higher vertical resolution. In contrast, the two COF-induced reflections are stronger than the conductivity-induced reflection in the $600 \mathrm{~ns}$ pulse data (Fig. 9a, blue). However, it is easier to trace the lateral extent of the COF-induced reflections in the $60 \mathrm{~ns}$ pulse data (Fig. 9b and d) than in the $600 \mathrm{~ns}$ pulse data.

Following the COF reflections in the wiggle plot of the $600 \mathrm{~ns}$ pulse (Fig. 9e) it becomes obvious that its characteristics are not as coherent in space as those of the conductivityinduced reflection. In both the 600 and $60 \mathrm{~ns}$ pulse data the strongest, most coherent reflector with laterally persistent attributes is the conductivity-induced event.

Based on these observations we conclude that the changes in COF are laterally much more variable than changes in conductivity. This intuitively makes sense, as changes in $\mathrm{COF}$ are developed in response to the local stress field within the ice, partly constrained by impurities, whereas changes in conductivity in the vertical resolution of our methods are formed by homogeneous deposition at the 10 to $100 \mathrm{~km}$ scale at the surface, with only slight post-depositional modification.

This finding is important for revisiting the physical properties of the echo-free zone (EFZ), which appears below $\sim 2200 \mathrm{~m}$ depth, where no clear events are observable in the radar data. Drews et al. (2009) discussed reasons for the EFZ at Kohnen Station and concluded that the EFZ is caused by layer roughness observed in line-scan data from the EDML ice core. Recent multi-static, phase-sensitive radar data show such rough basal layers above bedrock at many places in Antarctica (e.g. Gogineni, personal communication 2014; Dahl-Jensen et al., 2014; Ross and Siegert, 2014) as well as Greenland (e.g. NEEM community members, 2013). Thus, it is evident that the occurrence of the EFZ depends on the technical capabilities of the radar systems, especially lateral resolution and sensitivity.

In contrast to the radar data, a clear signal can be seen within the EFZ region in the seismic data at $2400 \mathrm{~m}$ depth (Fig. 8, event E). The different characteristics in radar and seismic data at this depth can be attributed to the different horizontal and vertical resolution of either method, i.e. the difference in the size of the first Fresnel zone and vertical resolution. The first Fresnel zone for the seismic wave at this depth, with a mean frequency of $\sim 140 \mathrm{~Hz}$, has a radius of about $180 \mathrm{~m}$. The first Fresnel zone for the radar wave, with a frequency of $150 \mathrm{MHz}$, is about $35 \mathrm{~m}$; i.e. the radar wave has a fivefold-higher resolution than the seismic wave. However, at the same time the reflected radar signal is influenced by the smaller scale roughness, as indicated by Drews et al. (2009), and the effective radar signal is weakened within the EFZ. Hence, we can put forward the conclusion that the upper limit of the roughness scale of the physical properties causing the EFZ in traditional radar systems is smaller than the lateral resolution of the seismic data.

\section{Conclusions}

Our analyses of the EDML ice core and seismic data in the vicinity of the borehole at Kohnen Station demonstrate that interval velocities determined from $\mathrm{COF}$ eigenvalues and VSP data are consistent within the available resolution and uncertainties. The choice of the monocrystal elasticity tensor for converting COF data to seismic velocities, however, has a strong influence on the results. Combining our findings with the result of Gusmeroli et al. (2012) raises the question of the frequency dependency of seismic wave velocities in ice. The components of the measured elasticity tensor should be considered to significantly depend not only on temperature (Gammon et al., 1983) but also on frequency. Further, based on the derived reliable depth conversion for the seismic data and the comparison to ice-core data, we conclude that observed englacial reflections in the seismic data are caused by short-scale changes in COF and are apparently not directly linked to grain size variations.

By comparing seismic, radar and ice-core data to determine the origin or radar reflections, we find that lateral characteristics of COF-induced radar reflections are subject to much more lateral variations than conductivity-induced reflections. Nevertheless, as the resolution of available COF data is not fine enough compared to the wavelengths of geophysical methods, there is still a need for very high resolution measurement with fabric analysers or ultrasonic logging on ice cores or in boreholes to fully understand the formation and distribution of crystal fabric and its interaction with impurities in the ice.

Without ice cores or seismic data at hand, it remains a challenge to single out COF-induced reflectors within the larger number of conductivity-induced reflections in radar data sets. Our approach shows how a combination with seismic data can considerably reduce ambiguities. We therefore recommend carrying out dedicated local seismic surveys during pre-site surveys of upcoming ice-core deep drilling projects, such as to retrieve Antarctica's oldest ice (Fischer et al., 2013). COF-based reflectors can be identified in combined data sets, and only those radar reflectors used for extrapolating already-established age-depth scales from other ice cores, which are purely caused by changes in conductivity and, thus, true isochrones. 
Our analysis of radar and seismic data within the radar EFZ allowed us to limit the previously unknown lateral roughness of physical properties to a scale smaller than the typical horizontal resolution on the order of $100 \mathrm{~m}$ (size of the first Fresnel zone) of the seismic data. While this could represent the specific ice-dynamic setting at the EDML drill site rather than a universally valid value, the progress in radar imaging in recent years and the widespread observation of a basal layer in Antarctica and Greenland confirm roughness scales of basal layers on the order of $100 \mathrm{~m}$. While it has already been shown that the palaeo-climate proxy records in such basal layers are most likely disturbed (e.g. NEEM community members, 2013), their role for ice viscosity and, thus, ice dynamics and flow still require further investigations.

Acknowledgements. We are grateful for the invaluable support of the AWI logistics team at Kohnen Station, especially Cord Drücker, Holger Wohltmann and Jens Köhler. We thank Rick Blenkner, Pascal Bohleber and Sverrir Hilmarsson for their support during the campaigns, as well as Thomas Bohlen and his group of the Karlsruhe Institute of Technology for their support during this study, especially Christopher Sanz for the picking of VSP travel times. We thank CIC, University of Copenhagen, for the provision of the temperature logger. Financial support for this study was provided to O. Eisen by the German Science Foundation (Deutsche Forschungsgemeinschaft, DFG) "Emmy Noether" program grant EI 672/5-1. I. Weikusat was supported by the Initiative and Networking Fund of the Helmholtz Association (HGF-VH-NG-802). This work was supported by the DFG in the framework of the priority programme "Antarctic research with comparative investigations in Arctic ice areas" by grant GA1271/8-1 to T. Binder. This work is a contribution to the European Project for Ice Coring in Antarctica (EPICA), a joint European Science Foundation-European Commission scientific programme, funded by the EU and by national contributions from Belgium, Denmark, France, Germany, Italy, the Netherlands, Norway, Sweden, Switzerland and the United Kingdom. The main logistic support was provided by IPEV and PNRA (at Dome C) and AWI (at Dronning Maud Land). This is EPICA publication no. 299. We thank A. Brisbourne and the anonymous reviewer for their comments, which greatly helped to improve the manuscript, and H. Gudmundsson for editing of this manuscript.

Edited by: G. H. Gudmundsson

\section{References}

Aki, K. and Richards, P. G.: Quantitative Seismology, University Science Books Sausalito, California, 2002.

Bass, R., Rossberg, D., and Ziegler, G.: Die elastischen konstanten des Eises, Zeitschr. f. Physik, 149, 199-203, 1957.

Bennett, H. F.: An investigation into velocity anisotropy through measurements of ultrasonic wave velocities in snow and ice cores from Greenland and Antarctica, $\mathrm{PhD}$ thesis, University of Wisconsin-Madison, 1968.

Bentley, C. R.: Seismic wave velocities in anisotropic ice: A comparison of measured and calculated values in and around the deep drill hole at Byrd Station, Antarctica, J. Geophys. Res., 77, 44064420, 1972.

Binder, T.: Measurements of grain boundary networks in deep polar ice cores-A digital image processing approach, $\mathrm{PhD}$ thesis, Ruperto-Carola University Heidelberg, Germany, 2014.

Brockamp, B. and Querfurth, H.: Untersuchungen über die Elastizitätskonstanten von See- und Kunsteis, Polarfoschung, 34, 253262, 1964.

Cuffey, K. M. and Paterson, W. S. B.: The Physics of Glaciers, Elsevier, Butterworth-Heineman, Amsterdam, 4th Edn., 2010.

Dahl-Jensen, D., Gogineni, S., and Panton, C.: Disturbed basal ice seen in radio echo images coincide with zones of big interlocking ice crystals, Geophys. Res. Abstr., 16, EGU2014-9677, 2014.

Daley, P. F. and Krebes, E. S.: Alternative linearized expressions for $\mathrm{qP}, \mathrm{qS} 1$ and $\mathrm{qS} 2$ phase velocities in a weakly anisotropic orthorhombic medium, CREWES Research Report, 16, 1-19, 2004.

Dantl, G.: Die elastischen Moduln von Eis-Einkristallen, Phys. Kondens. Materie, 7, 390-397, 1968.

Diez, A. and Eisen, O.: Seismic wave propagation in anisotropic ice - Part 1: Elasticity tensor and derived quantities from ice-core properties, The Cryosphere, 9, 367-384, doi:10.5194/tc-9-3672015, 2015.

Drews, R., Eisen, O., Weikusat, I., Kipfstuhl, S., Lambrecht, A., Steinhage, D., Wilhelms, F., and Miller, H.: Layer disturbances and the radio-echo free zone in ice sheets, The Cryosphere, 3, 195-203, doi:10.5194/tc-3-195-2009, 2009.

Drews, R., Martin, C., Steinhage, D., and Eisen, O.: Characterizing the glaciological conditions at Halvfarryggen ice dome, Dronning Maud Land, Antarctica, J. Glaciol., 59, 9-20, 2013.

Eisen, O., Wilhelms, F., Steinhage, D., and Schwander, J.: Instruments and Methods: Improved method to determine radio-echo sonding reflector depth from ice-core profiles of permittivity and conductivity, J. Glaciol., 52, 299-310, 2006.

Eisen, O., Hamann, I., Kipfstuhl, S., Steinhage, D., and Wilhelms, F.: Direct evidence for continuous radar reflector originating from changes in crystal-orientation fabric, The Cryosphere, 1, 1-10, doi:10.5194/tc-1-1-2007, 2007.

Eisen, O., Hofstede, C., Diez, A., Kristoffersen, Y., Lambrecht, A., Mayer, C., Blenkner, R., and Hilmarsson, S.: On-ice vibroseis and snowstreamer systems for geoscientific research, Polar Sci., doi:10.1016/j.polar.2014.10.003, in press, 2014.

Faria, S. H., Weikusat, I., and Azuma, N.: The microstructure of polar ice. Part II: State of the art, J. Struct. Geol., 61, 21-49, 2014.

Fischer, H., Severinghaus, J., Brook, E., Wolff, E., Albert, M., Alemany, O., Arthern, R., Bentley, C., Blankenship, D., Chappellaz, J., Creyts, T., Dahl-Jensen, D., Dinn, M., Frezzotti, M., Fujita, S., Gallee, H., Hindmarsh, R., Hudspeth, D., Jugie, G., Kawamura, K., Lipenkov, V., Miller, H., Mulvaney, R., Parrenin, F., Pattyn, F., Ritz, C., Schwander, J., Steinhage, D., van Ommen, T., and Wilhelms, F.: Where to find 1.5 million yr old ice for the IPICS "Oldest-Ice" ice core, Clim. Past, 9, 2489-2505, doi:10.5194/cp9-2489-2013, 2013.

Fujita, S., Matsuoka, T., Ishida, T., Matsuoka, K., and Mae, S.: A summary of the complex dielectric permittivity of ice in the megahertz range and its application for radar sounding of polar ice sheets, in: The physics of ice core records, edited by: Hondoh, T., 185-212, Hokkaido University Press, 2000. 
Gammon, P. H., Kiefte, H., Clouter, M. J., and Denner, W. W.: Elastic constant of artificial and natural ice samples by brillouin spectroscopy, J. Glaciol., 29, 433-460, 1983.

Gow, A. J. and Meese, D.: Physical properties, crystalline textures and c-axis fabrics of the Siple Dome (Antarctica) ice core, J. Glaciol., 53, 573-584, 2007.

Green, R. E. and Mackinnen, L.: Determination of the Elastic Constrants of Ice Single Crystals by an Ultrasonic Pulse Method, J. Acoust. Soc. Am., 28, p. 1292, doi:10.1121/1.1908626, 1956.

Gusmeroli, A., Pettit, E. C., Kennedy, J. H., and Ritz, C.: The crystal fabric of ice from full-waveform borehole sonic logging, J. Geophys. Res., 117, F03021, doi:10.1029/2012JF002343, 2012.

Hamann, I., Kipfstuhl, S., and Lambrecht, A.: Fabrics and grainshape orientations in EDML ice core, Antarctica, in: The 28th NIPR Symposium on Polar Meteorology and Glaciology, 30 November-1 Dezember, 2005 National Institute of Polar Research, Tokyo, Japan, 2005.

Jona, F. and Scherrer, P.: Die elastischen Konstanten von EisEinkristallen, Helvetica Phys. Act., 25, 35-54, 1952.

Kohnen, H.: The temperature dependence of seismic waves in ice, J. Glaciol., 13, 144-147, 1974.

Matsuoka, T., Fujita, S., Morishima, S., and Mae, S.: Precise measurement of dielectric anisotropy in ice Ih at $39 \mathrm{GHz}$, J. Appl. Phys., 81, 2344-2348, 1997.

NEEM community members: Eemian interglacial reconstructed from a Greenland folded ice core, Nature, 493, 489-494, 2013.
Oerter, H., Drücker, C., Kipfstuhl, S., and Wilhelms, F.: Kohnen Station-the Drilling Camp for the EPICA Deep Ice Core in Dronning Maud Land, Polarforschung, 78, 1-23, 2009.

Penny, A. H. A.: A theoretical determination of the elastic constants of ice, Math. Proc. Cambridge Philosoph. Soc., 44, 423-439, 1948.

Ross, N. and Siegert, M.: Concentrated englacial shear over rigid basal ice, West Antarctica: implications for modelling and ice sheet flow, Geophys. Res. Abstr., 16, EGU2014-5568, 2014.

Svensson, A., Bigler, M., Blunier, T., Clausen, H. B., Dahl-Jensen, D., Fischer, H., Fujita, S., Goto-Azuma, K., Johnsen, S. J., Kawamura, K., Kipfstuhl, S., Kohno, M., Parrenin, F., Popp, T., Rasmussen, S. O., Schwander, J., Seierstad, I., Severi, M., Steffensen, J. P., Udisti, R., Uemura, R., Vallelonga, P., Vinther, B. M., Wegner, A., Wilhelms, F., and Winstrup, M.: Direct linking of Greenland and Antarctic ice cores at the Toba eruption (74 ka BP), Clim. Past, 9, 749-766, doi:10.5194/cp-9-749-2013, 2013.

Weikusat, I., Kipfstuhl, S., Faria, S. H., Azuma, N., and Miyamoto, A.: Subgrain boundaries and related microstructural features in EDML (Antarctica) deep ice core, J. Glaciol., 55, 461-472, 2009.

Wilhelms, F., Sheldon, S. G., Hamann, I., and Kipfstuhl, S.: Implications for and findings from deep ice core drillings an example: The ultimate tensile strength of ice at high strain rates, Physics and Chemistry of Ice (The proceedings of the International Conference on the Physics and Chemistry of Ice held at Bremerhaven, Germany on 23-28 July 2006) The Royal Society of Chemistry Special Publication No. 311, 635-639, 2007. 